\title{
Absent right superior caval vein (vena cava) with normal atrial arrangement
}

\author{
JUNG Y CHOI, * ROBERT H ANDERSON, $†$ FERGUS J MACARTNEY * \\ From the ${ }^{\star}$ Department of Paediatric Cardiology, The Hospital for Sick Children, Great Ormond Street, and \\ the $†$ Cardiothoracic Institute, London
}

SUMMARY Eight cases of absent right superior caval vein (vena cava) with normal atrial arrangement from the Great Ormond Street database were reviewed. In each case the right subclavian vein and jugular vein drained into a persistent left superior caval vein through a bridging vein. In six cases the left superior caval vein drained into the right atrium by way of the coronary sinus, and in two cases it drained into the left atrium directly because of the complete unroofing of the coronary sinus. The frontal plane $P$ wave axis was displaced leftwards and upwards in four out of seven cases in which an electrocardiogram was available. No case showed arrhythmia on a standard electrocardiogram preoperatively. Echocardiograms were available in four cases and in each case diagnosis of the anomalous connections of the systemic vein was possible. Only one third of the cases showed a crescentic shadow of the persistent left superior caval vein on chest $x$ ray.

A chest $x$ ray and electrocardiogram do not provide the means of reliable diagnosis of this condition, though they may suggest the possibility of its existence. Definitive diagnosis requires cross sectional echocardiography or angiocardiography or both.

Systemic venous anomalies are not uncommon in congenital heart disease particularly in atrial isomerism. When the atria are normally arranged a persistent left superior caval vein (vena cava) is the most common systemic venous anomaly and usually drains into the right atrium by way of the coronary sinus.

Absence of the right superior caval vein in atrial situs solitus is very rare and may present with either total absence of superior vena cava or partial absence above the azygos vein. ${ }^{12}$ When the right superior caval vein is absent there is always a left superior caval vein that usually empties by way of the coronary sinus into the right atrium. ${ }^{34}$ The left superior caval vein may join the left atrium directly in patients with normal atrial arrangement, in which case all the systemic venous blood from the upper half of the body drains into the left atrium. ${ }^{56}$

A persistent left superior caval vein draining into the right atrium by way of the coronary sinus is haemodynamically insignificant unless the patient is to undergo cardiopulmonary bypass, a surgical pro-

Requests for reprints to Professor Fergus J Macartney, The Hospital for Sick Children, Great Ormond Street, London WC1N 3JH.

Accepted for publication 18 December 1986 cedure involving the systemic veins, or pacemaker insertion. ${ }^{7-10}$ When the left superior caval vein drains directly into the left atrium it can produce a right to left shunt and cyanosis. ${ }^{11}$

A persistent left superior caval vein is often associated with leftward deviation of the $P$ wave axis and other arrhythmias. ${ }^{3912}$ There has been a debate on the mechanism of these arrhythmias and abnormal histological findings in the conduction system have been reported. ${ }^{213}$

The diagnosis of persistent left superior caval vein once required diagnosis by catheterisation or angiocardiography or both, but now non-invasive diagnosis by echocardiography is possible. ${ }^{14}$

\section{Patients and methods}

The Great Ormond Street database, consisting of computerised records of necropsies since 1940 and diagnoses in life since 1972, was searched for cases of absent right superior caval vein in patients with normal atrial arrangement and absent left superior caval vein in those with inverted atria. Eight patients in the former category were found and none in the latter. Patients with atrial isomerism were excluded. Cardiac catheterisation and angiocardiography were 
Table Cardiac anomalies in eight cases of absent right superior caval vein

\begin{tabular}{|c|c|c|c|}
\hline Case No. & Age & Sex & Cardiac anomalies \\
\hline 1 & 2 yr 5 mnth & $\mathbf{M}$ & $\begin{array}{l}\text { Solitus, discordant, single outlet heart with aorta from right ventricle. Pulmonary } \\
\text { atresia. Dextrocardia. VSD, ASD, DA }\end{array}$ \\
\hline 2 & 2 yr 8 mnth & $\mathbf{M}$ & Normal connections. VSD \\
\hline 3 & 1 yr 8 mnth & $\mathbf{F}$ & Normal connections. TOF. Right aortic arch \\
\hline 4 & 5 yr 7 mnth & $\mathbf{F}$ & Normal connections. TOF \\
\hline 5 & 7 mnth & $\mathbf{M}$ & $\begin{array}{l}\text { Normal connections. Left superior caval vein to left atrium because of complete } \\
\text { unroofing of coronary sinus }\end{array}$ \\
\hline 6 & 1 day & $\mathbf{M}$ & $\begin{array}{l}\text { Solitus, concordant, single outlet heart with aorta from right ventricle. VSD, DA. } \\
\text { Left juxtaposition of atrial appendages. Right aorta arch. Complete unroofing of } \\
\text { coronary sinus }\end{array}$ \\
\hline $\begin{array}{l}7 \\
8\end{array}$ & $\begin{array}{l}2 \text { wk } \\
5 \text { yr } 6 \text { mnth }\end{array}$ & $\begin{array}{l}\mathbf{M} \\
\mathbf{M}\end{array}$ & $\begin{array}{l}\text { Solitus, concordant, single outlet truncus arteriosus. ASD, VSD } \\
\text { Normal connections. Coarctation of aorta }\end{array}$ \\
\hline
\end{tabular}

VSD, ventricular septal defect; ASD, atrial septal defect; DA, ductus arteriosus; TOF, tetralogy of Fallot.

carried out in all cases and heart surgery was performed in six. Necropsy specimens were available in two cases.

\section{Results}

There were eight cases of absence of right superior caval vein. All had other cardiovascular anomalies (table). In each case the right jugular and subclavian veins drained into the left superior caval vein by way of a bridging brachiocephalic vein. The left superior caval vein drained into the right atrium by way of the coronary sinus in six cases. In two cases the left superior caval vein drained into the left atrium because of complete unroofing of the coronary sinus. The only remnant of the coronary sinus was its orifice, which mimicked an atrial septal defect. Pathological specimens were available in cases 6 and 7. In both cases there was no remnant of the right superior caval vein, not even a fibrous chord.

Standard electrocardiograms were available in seven cases. Frontal plane $\mathbf{P}$ wave axes were variable, ranging from $-30^{\circ}$ to $60^{\circ}$. Four cases showed an upwards and leftwards deviation of the $P$ wave axis, but in no case was deviation extreme (less than $-30^{\circ}$ ). In three cases the $P$ wave axis was within the normal range $\left(0-90^{\circ}\right)$. P-R intervals were in the normal range except in one case which showed a shortened P-R interval (0.10 s), no P-R segment, and a normal $P$ wave axis. No case showed any arrhythmia preoperatively on a standard electrocardiogram. Conduction anomalies developed in three cases after operation. In case 4 complete right bundle branch block developed after total correction of tetralogy of Fallot. Case 5 showed transient second or third degree heart block during the first three days after an operative procedure in the coronary sinus area. The cardiac rhythm returned to normal three days after operation and a follow up electrocardiogram did not show any arrhythmia. In case 3 complete right bundle branch block developed after total correction of tetralogy of Fallot and 24 hour electrocardiographic monitoring showed sinus slowing with junctional escape during sleep. The QRS axis and evidence of ventricular hypertrophy varied depending on the associated intracardiac anomalies. There were no cases with intraventricular conduction abnormalities before surgery.

Chest $x$ rays were available in seven cases. Cardiac size and shape and pulmonary vascular markings depended upon the associated cardiac defects. The superior mediastinal shadow on both sides of the spine was evaluated. A crescentic vascular shadow passing from the upper left border of the aortic arch towards the middle third of the left clavicle was evident in two cases out of seven. Case 2 showed a decreased mediastinal shadow to the right of the

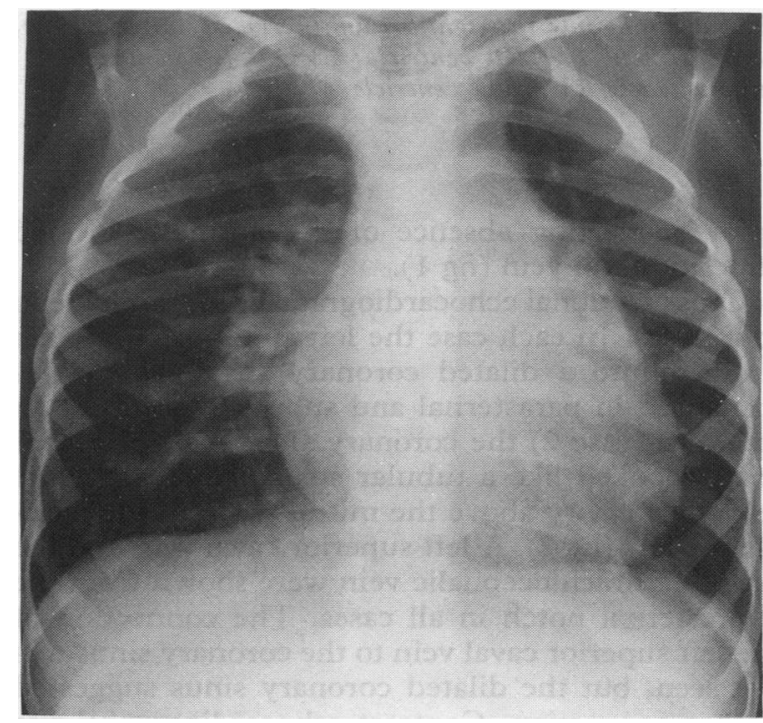

Fig 1 Chest posterior-anterior $x$ ray of case 2 showing absence of the usual shadow to the right of the spine above the right atrial shadow suggesting absence of right superior caval vein. 

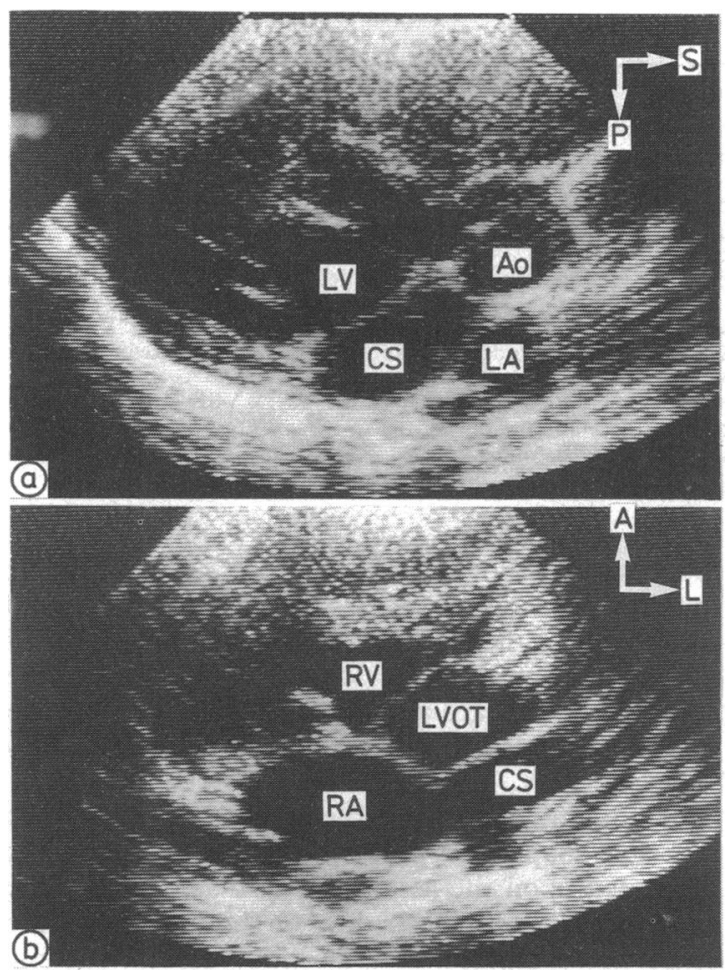

Fig 2 Cross sectional echocardiogram of case 2. Upper picture is a precordial long axis cut showing dilated coronary sinus (CS) which looks like a tubular structure in the left atrium ( $L A)$. Lower picture is a precordial short axis cut just below the aortic valve showing the coronary sinus draining into the right atrium $(R A)$. A, anterior; Ao, aorta; $L$, left; $L V$, left ventricle; $L V O T$, left ventricular outflow tract; $R V$, right ventricle.

spine suggesting absence of the normally located superior caval vein (fig 1 ).

Cross sectional echocardiograms were available in four cases. In each case the left superior caval vein drained into a dilated coronary sinus which was visualised in parasternal and subcostal sections. In one case (case 2) the coronary sinus was so dilated that it looked like a tubular structure crossing the left atrial cavity above the mitral valve in the parasteral view (fig 2). A left superior caval vein and the bridging brachiocephalic vein were shown from the suprasternal notch in all cases. The connection of the left superior caval vein to the coronary sinus was not seen, but the dilated coronary sinus suggested such a connection. Contrast echocardiography was done in one case and proved the absence of a right superior caval vein and the connection of the persistent left superior caval vein to the coronary sinus.

\section{Discussion}

A persistent left superior caval vein draining into the coronary sinus is the most frequent type of systemic venous anomaly found when the atrial arrangement is normal; the abnormality is usually associated with a right superior caval vein in the normal position. ${ }^{15}$ Rarely the persistent left superior caval vein drains into the left atrium; in this condition the coronary sinus may or may not be absent. ${ }^{56}$ Raghib and associates described five cases in which the left superior caval vein terminated in the left atrium with atrial septal defect and absence of coronary sinus. These workers speculated that all these anomalies could have originated from a single anomalous developmental complex. ${ }^{11}$

The embryology of and anatomical variation in cases of a persistent left superior caval vein are discussed in detail elsewhere. ${ }^{11516}$ The origin of the left superior caval vein may be attributed to the persistence of the anterior cardinal vein with its caudal junction with the left duct of Cuvier. If, for unknown reasons, flow through the brachiocephalic vein is reversed and the right cephalic region drains into the left anterior cardinal vein an atretic or absent right superior caval vein will result. ${ }^{4}$

Although a persistent left superior caval vein draining into the right atrium by way of the coronary sinus has no significant haemodynamic effect, it is very important to know of its presence when a patient undergoes either open heart surgery with cardiopulmonary bypass, the Glenn procedure, Mustard's operation, or transvenous pacemaker insertion. ${ }^{7-917}$ The problems which this abnormality may present and possible solutions have been reviewed. ${ }^{310}$ When the persistent left superior caval vein drains into the left atrium, an intracardiac right to left shunt forms a part of the functional abnormality and cerebral complications may occur. ${ }^{11}$ If this venous anomaly is associated with other intracardiac anomalies, preoperative diagnosis of the connection of the left superior caval vein to the left atrium is important, particularly in those congenital defects in which the right atrial pressure after operation tends to be higher than the left atrial pressure. An undetected left superior caval vein may result in a large residual right to left shunt, cyanosis, and suboptimal cardiac performance in the immediate postoperative period.

The diagnosis of a persistent left superior cava was usually made at cardiac catheterisation, at operation, or at necropsy. A persistent left superior caval vein may be suspected when the chest $x$ ray shows an extra structure in the area of the aortic knob and upper mediastinum ${ }^{16}$ but this is not a sensitive finding. Non-invasive diagnosis of systemic venous 
anomalies is possible by echocardiography. ${ }^{141819}$ The echocardiographic findings when there is a persistent connection between the left superior caval vein and the coronary sinus have been described. ${ }^{20} 21 \mathrm{M}$ mode echocardiography shows an abnormal linear echo behind the mitral valve with a phasic movement similar to the aortic leaflet of the mitral valve. The cross sectional echocardiogram demonstrates a dilated coronary sinus on various views. Suprasternal echocardiography is very useful in delineating supracardiac anatomy. In the suprasternal paracoronal view the innominate vein and normally placed right superior caval vein are visualised with the right pulmonary artery and aorta. The left superior caval vein, when present, is seen apparently crossing the upper descending aorta, provided the latter is on the left, as the transducer is rotated and/or tilted to the left. ${ }^{19}$ Direct echocardiographic diagnosis of absent right superior caval vein is also possible. ${ }^{1419}$ The connection of left superior caval vein to the heart is difficult to visualise directly, but it is usually predictable on the basis of associated findings. ${ }^{14}$ When a clear suprasternal view is not available or there is any doubt, contrast echocardiography may be very helpful in confirming the venous connection to the heart. ${ }^{1822}$ Huhta and colleagues examined the sensitivity and specificity of echocardiography in diagnosing anomalous systemic venous return and concluded that cross sectional echocardiography was an extremely specific and highly sensitive method of recognising anomalous venous return. ${ }^{14}$

Absence of the right superior caval vein might well be expected to result in anomalous positioning of the sinoatrial node, which normally lies at the junction between the superior caval vein and right atrium. Half of our cases showed a superior leftwards deviation of the $\mathbf{P}$ wave axis; sinus slowing with junctional escape was detected in one case after open heart surgery. No case showed arrhythmia on a standard electrocardiogram before operation.

When a persistent left superior caval vein is present the electrocardiogram often shows an abnormal $P$ wave axis and a normal or shortened $P-R$ interval. ${ }^{31223}$ The mechanism of the leftwards deviation of the $P$ wave axis is not clear. It has been attributed to the presence of an ectopic pacemaker around the coronary ostium, ${ }^{12}$ but histological study clearly showed a normally placed sinoatrial node and absence of any pacemaker anywhere around the coronary ostium. ${ }^{2}{ }^{13}$ A geometric change of the left atrium may be a possible mechanism of left axis deviation of the $\mathbf{P}$ wave. Dilatation of the coronary sinus, which has to transmit all blood from the upper half of the body, may alter the geometry of the atrium and displace the left atrium upwards. ${ }^{12}$
Besides the leftward deviation of the $P$ wave axis, there have been reports of various arrhythmias in this anomaly. ${ }^{913}$ James and colleagues made a detailed pathological study in two teenage boys with absent right superior caval vein. One died suddenly and the other died of arrhythmia 16 days after repair of ventricular septal defect. The first patient had a small sinus node and the second had a mass of polypoid tissue blocking the artery supplying the sinus node. In both the atrioventricular node was fragmented and stretched out over the large coronary sinus. They speculated that these histological abnormalities might be responsible for electrical instability of the heart and recommended detailed studies of the conduction system when there is a persistent left superior caval vein. ${ }^{13}$

Lenox and colleagues collected 11 cases of arrhythmia among published reports of 60 cases with absent right superior caval vein and suggested a possible predisposition to arrhythmia in this anomaly. ${ }^{3}$ The same group recently reported on a pathological study on the conduction tissue in hearts with varying degrees of coronary sinus dilatation including four cases in which the right superior caval vein was absent. ${ }^{2}$ They found that the size of the coronary sinus did not alter the histology of the adjacent conduction tissue. When the right superior caval vein was absent the sinoatrial node was normally placed and the atrioventricular conduction tissues were normal. But the sinoatrial node was hypoplastic in three out of four cases of absent right superior caval vein. They suggested that the development of atrioventricular nodal component is independent of the development of coronary sinus and that a hypoplastic sinoatrial node may predispose to the sick sinus syndrome. Although there have been reports of arrhythmia in cases of absent right superior caval vein, it is very difficult to know the true frequency of arrhythmia in these cases. It is even more difficult to ascertain the causal relation between arrhythmia and the occurrence of absent right superior caval vein. Hypoplasia of the sinoatrial node, however, suggests the possible development of sinus node dysfunction in this anomaly. If the true frequency of arrhythmia and the functional significance of hypoplastic sinoatrial node are to be determined long term follow up study and perhaps electrophysiological evaluation are needed.

JYC is a member of the School of Paediatric Cardiology and is supported by the British Council. RHA is supported by the Joseph Levy Foundation, FJM by the Vandervell Foundation, and both are supported by the British Heart Foundation. 


\section{References}

1 Winter FS. Persistent left superior vena cava; survey of world literature and report of thirty additional cases. Angiology 1954;5:90-132.

2 Lenox CC, Hashida Y, Anderson RH, Hubbard JD. Conduction tissue anomalies in absence of the right superior caval vein. Int $\mathcal{f}$ Cardiol 1985;8:251-60.

3 Lenox CC, Zuberbuhler JR, Park SC, et al. Absent right superior vena cava with persistent left superior vena cava: implications and management. $\mathrm{Am} \mathcal{f} \mathrm{Car}$ diol 1980;45:117-22.

4 Garcia JM, Sanmarti J, Moller JH. Congenital absence of the right superior vena cava: report of two cases. Eur f Cardiol 1978;7:293-7.

5 Kabbani SS, Feldman M, Angelini P, Leachman RD, Cooley DA. Single (left) superior vena cava draining into the left atrium. Ann Thorac Surg 1973; 16:518-25.

6 Sherafat M, Friedman S, Waldhausen JA. Persistent left superior vena cava draining into the left atrium with absent right superior vena cava. Ann Thorac Surg 1971;11:160-4.

7 Garcia JM. Absent right superior vena cava. Am $\mathcal{f}$ Cardiol 1980;46:714-5.

8 Harris A, Gialafos J, Jefferson K. Transvenous pacing in presence of anomalous venous return to heart. $\mathrm{Br}$ Heart $\mathcal{F}$ 1972;34:1189-91.

9 Camm AJ, Dymond D, Spurrell RAJ. Sinus node dysfunction associated with absence of right superior vena cava. Br Heart $\mathcal{F}$ 1979;41:504-7.

10 De Leval MR, Ritter DG, McGoon DC, Danielson GK. Anomalous systemic venous connection. Surgical considerations. Mayo Clin Proc 1975;50: 599-610.

11 Raghib G, Ruttenberg HD, Anderson RC, Amplatz K, Adams P Jr, Edwards JE. Termination of left superior vena cava in left atrium, atrial septal defect, and absence of coronary sinus. A developmental complex. Circulation 1965;31:906-18.

12 Momma K, Linde LM. Abnormal rhythms associated with persistent left superior vena cava. Pediatr Res 1969;3:210-6.

13 James TN, Marshall TK, Edwards JE. Cardiac electrical instability in the presence of a left superior vena cava. Circulation 1976;54:689-97.

14 Huhta JC, Smallhorn JF, Macartney FJ, Anderson RH, de Leval M. Cross-sectional echocardiographic diagnosis of systemic venous return. Br Heart $J$ 1982;48:388-403.

15 Campbell M, Deuchar DC. The left-sided superior vena cava. Br Heart $J$ 1954;16:423-39.

16 Fraser RS, Drorkin J, Rossall RE, Eidem R. Left superior vena cava: a review of associated congenital heart lesions, catheterization data and roentgenologic findings. Am J Med 1961;31:711-6.

17 Garcia L, Levine RS, Kossowsky W, Lyon AF. Persistent left superior vena cava complicating pacemaker catheter insertion. Chest 1972;61:396-7.

18 Foale R, Bourdillon PD, Somerville J, Richards A. Anomalous systemic venous return: recognition by two-dimensional echocardiography. Eur Heart J 1983;4:186-95.

19 Snider AR, Silverman NH. Suprasternal notch echocardiography: a two-dimensional technique for evaluating congenital heart disease. Circulation 1981; 63:165-73.

20 Hibi N, Fukui Y, Nishimura K, Miwa A, Kambe T, Sakamoto N. Cross-sectional echocardiographic study on persistent left superior vena cava. Am Heart $J$ 1980;100:69-76.

21 Snider AR, Ports TA, Silverman NH. Venous anomalies of the coronary sinus: detection by $\mathrm{M}$-mode, two-dimensional and contrast echocardiography. Circulation 1979;60:721-7.

22 Oguni H, Hatano T, Yamada T, et al. A case of absent right superior vena cava with persistent left superior vena cava: cross-sectional echocardiographic diagnosis. Heart and Vessels 1985;1:239-43.

23 Hancock EW. Coronary sinus rhythm in sinus venosus defect and persistent left superior vena cava. Am J Cardiol 1964;14:608-15. 